\title{
FORMAÇÃO DE PROFESSORES NA CONTEMPORANEIDADE: CONSIDERAÇÕES REFLEXIVAS NO ÂMBITO DA UNIVERSIDADE
}

Teacher Training in Contemporaneity: reflective considerations in university context

Formación del Profesorado en Contemporánea: consideraciones reflectante en el contexto universitario

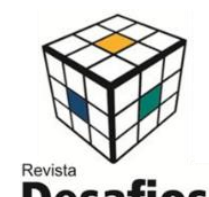

Desafios

Artigo Original

Original Article

Artículo Original

\author{
Maria José de Pinho* ${ }^{1}$, Juliane Gomes de Sousa ${ }^{1}$, Tatiane da Costa Barros ${ }^{1}$ \\ ${ }^{1}$ Universidade Federal do Tocantins. PPGE/ UFT, Araguaína, Tocantins, Brasil. \\ *Correspondência: Programa de Pós-Graduação em Ensino de Língua e Literatura (PPGL) - Centro de Ciências \\ Integradas (Unidade Cimba), Avenida Paraguai, s $n^{\circ}$, esquina com a Rua Uxiramas, Setor Cimba, Araguaína, \\ Tocantins, Brasil.CEP: 77824-838.e-mail: mjpigon@uft.edu.br
}

Artigo recebido em 20/06/2016. Aprovado em 01/06/2016. Publicado em 23/11/2016.

\section{RESUMO}

O presente artigo é fruto das discussões realizadas no GT do Curso de Pedagogia durante o II Fórum das Licenciaturas da Universidade Federal do Tocantins, com o tema "Os novos desafios curriculares: a formação de professores em discussão". O texto tem por objetivo trazer à tona algumas reflexões acerca do papel da universidade na formação de professores frente aos novos desafios para o Ensino Superior. O procedimento adotado para o alcance do objetivo caminha pela abordagem qualitativa e de caráter bibliográfico. No bojo dos levantamentos e questionamentos apresentados, buscou-se provocar reflexões no sentido de contribuir com as discussões acerca do papel da Universidade no contexto das mudanças atuais. Com isso, é evidenciado que o papel da Universidade na formação de professores na sociedade do conhecimento, deve encaminhar-se para intensas transformações, o que a direciona para uma atitude de vigilância quanto a sua missão, nessa era que exige uma formação cada vez mais condizente com as novas demandas oriundas do contexto social.

Palavras- chave: Universidade. Formação de professores. Contemporaneidade.

\section{ABSTRACT}

This article is the result of discussions held in the Pedagogy course of GT during the II Forum of Undergraduate the Federal University of Tocantins, with the theme "The new curriculum challenges: the training of teachers in discussion." The text aims to bring to light some reflections on the role of the university in the training of teachers facing new challenges for higher education. The procedure adopted for the purpose of reaching walks the qualitative approach and bibliographic. In the midst of the submitted surveys and questions, we sought to provoke reflections to contribute to discussions about the role of the University in the context of current changes. Thus, it is evident that the role of the University in teacher education in the knowledge society, should be heading to intense transformations, which directs for vigilance as its mission, in this era that requires training increasingly consistent with the new demands from the social context.

Keywords: University. Teacher training. Contemporaneity

\section{RESUMEN}

Este artículo es el resultado de los debates en curso de educación WG durante el II Foro de Pregrado de la Universidad Federal de Tocantins, con el tema "Los nuevos desafíos del plan de estudios: la formación de los profesores en la discusión." El texto tiene como objetivo dar a conocer algunas reflexiones sobre el papel de la universidad en la formación de los profesores se enfrentan a nuevos retos para la educación superior. El procedimiento adoptado con el propósito de alcanzar camina el enfoque cualitativo y bibliográfica. En medio de 
las encuestas y las preguntas presentadas, hemos tratado de provocar reflexiones para contribuir a las discusiones sobre el papel de la Universidad en el contexto de los cambios actuales. Por lo tanto, es evidente que el papel de la Universidad en la formación docente en la sociedad del conocimiento, debe ser de dirigirse a intensas transformaciones, que dirige a la vigilancia como misión, en esta época que requiere una formación cada vez en consonancia con las nuevas exigencias del contexto social.

Palabras clave: Universidad. Formación de profesores. contemporaneidad

\section{NOTAS INTRODUTÓRIAS}

"Universidade é o lugar privilegiado de uma formação adaptada às exigências de nosso tempo, o eixo de uma formação dirigida aos adultos que acaba alcançando também as crianças e adolescentes". (NICOLESCU, 1999, p. 150)

A contemporaneidade é marcada por grandes transformações sociais, em especial as de ordenamento científico e tecnológico, caracterizadas por tensões que se apresentam no contexto social, político e cultural, e que por sua vez tendem a refletir no campo da educação, haja vista que é por meio dela que se busca assegurar as transformações pensadas e discutidas pelas demais esferas.

Considerando a importância da universidade como uma instituição que acompanha as transformações sociais, econômicas e políticas primando pelo princípio democrático, a relação entre universidade e sociedade deve ser de interação, uma vez que esta, como instituição social formativa, contribui para o modo de funcionamento da sociedade, por se constituir como lócus privilegiado de produção e disseminação de conhecimento.

Com isso, de acordo com Pimenta e Anastasiou (2002), a formação dos sujeitos como trabalho da universidade enfrenta constantes desafios na contemporaneidade, e por isso é tão importante destacar as funções formativas desta instituição, as quais sejam:

Criação, desenvolvimento, transmissão e crítica da ciência, da técnica e da cultura; preparação para o exercício de atividades profissionais que exijam a aplicação de conhecimentos e métodos científicos e para a criação artística; apoio científico e técnico ao desenvolvimento cultural, social e econômico das sociedades (PIMENTA; ANASTASIOU, 2002, p.163).

E nesse cenário as universidades enfrentam vários desafios, sejam de ordem social, as quais têm se deparado com novas demandas do mundo globalizado e do mercado produtivo; política, em que cada vez mais sofrem com pressões de poderes políticos que lhes impõem mecanismos de controle; e econômica, há um movimento crescente de escassez de recursos. Diante esses aspectos, que se apresentam desafiadores, faz com que sejam requeridas mudanças paradigmáticas no contexto pessoal e coletivo da universidade, passando a exigir uma ressignificação de sua estrutura e função, bem como explicitam a necessária atenção para a complexidade existente no âmbito da educação.

É importante ressaltar que a universidade também passa por momentos de crise, que nas palavras de Santos (2004), no contexto atual, se materializa por meio da tríade crísica: de hegemonia, de legitimidade e institucional, o que a leva a enfrentar dificuldades quanto ao papel de produzir e difundir os conhecimentos indispensáveis na atualidade.

Nesse escopo, é necessária uma reconfiguração acerca do ensino e do papel da universidade enquanto difusora do conhecimento, frente às novas necessidades que ora se apresentam e demanda um novo olhar, o momento atual se apresentando oportuno para a concretização deste objetivo haja 
vista que, “[...] quando há crise, há o prenúncio de mudança”. (BARRETO et al., 2013, p. 83).

No bojo dessas discussões, é conferida à educação uma relevância indiscutível, pois, ela é fator fundamental para a busca da igualdade social, desenvolvimento humano, científico, econômico, político, tecnológico e cultural, e a universidade não foge a esta lógica, dado a importância e compromisso social atribuído ao seu papel.

Dessa forma, a partir das discussões levantadas no Grupo de Trabalho (GT) ${ }^{1}$ dos Cursos de Pedagogia, ofertados na Universidade Federal do Tocantins (UFT), durante o II Fórum das Licenciaturas, organizado pela Pró-reitoria de Graduação (PROGRAD), realizado nos dias 26 e 27 de abril do ano de 2016, com o tema "Os novos desafios curriculares: a formação de professores em discussão", surgiram algumas inquietações acerca da formação que a universidade, de modo geral, e com um olhar mais atento no cenário institucional da UFT, vem encaminhando no atual contexto, dentre elas a seguinte: Qual o papel da universidade na formação de professores na contemporaneidade?.

Diante disso, o presente texto busca tecer algumas reflexões e apontamentos a partir das discussões do GT dos cursos de Pedagogia, bem como do mergulho teórico junto aos estudiosos que discutem as questões do ensino superior, dentre eles, destacamos: Zabalza (2004), Morin (2002), Nóvoa (1992, 1997, 2007), Pimenta e Anastasiou (2002), Imbernón, (2011), Libâneo (2009), os quais foram elencados para o estudo, proposto, dada a relevância de suas análises em torno do tema abordado. O percurso metodológico caminha para a abordagem da

\footnotetext{
1 No referido GT reuniram-se docentes dos 04 cursos de Pedagogia da Universidade Federal do Tocantins contemplando os seguintes câmpus: Arraias, Tocantinópolis, Palmas e Miracema. O evento ocorreu entre os dias 26 e 27 de abril de 2016 no Câmpus Universitário de Palmas/ TO.
}

pesquisa qualitativa de caráter bibliográfico, recorrendo-se a referenciais teóricos que sustentam a discussão apresentada, bem como a observação in lócus das atividades desenvolvidas no evento referenciado. Assim, lançando mão do arcabouço teórico, buscou-se sustentar análises que intercruzam teoria com fatos retirados do processo desencadeado no GT de Pedagogia.

Assim sendo, o artigo está dividido em dois tópicos que se complementam entre si: no tópico 1 , são apresentados alguns apontamentos acerca dos desafios que se vinculam à universidade na contemporaneidade, inicialmente em um contexto mais amplo para, posteriormente, levantar algumas reflexões no cenário específico dos cursos de Pedagogia da UFT; no tópico 2, são pontuadas reflexões que visam provocar uma discussão acerca da formação e do papel do professor. Com isso, também são elencadas algumas considerações finais, que se validam antes como considerações propositivas.

\section{OS DESAFIOS DA UNIVERSIDADE NA CONTEMPORANEIDADE}

Partindo do entendimento de que a educação é o elemento basilar na construção de uma sociedade do conhecimento, ensinar requer uma ampliação de possibilidades da prática pedagógica, em que não mais comporta um ensino conteudista, repetitivo e fragmentado, fundamentado na memorização de conceitos. Morin (2002) aponta que é preciso aprender a situar os conhecimentos, dado que o mesmo avança não tão somente pela formalização e abstração, mas em especial, pela nossa capacidade de contextualizar e compreender.

No cenário atual, segundo Zabalza (2004), a universidade tem fundamental importância no processo de formação, mas não o encerra, uma vez 
que esse se inicia antes da chegada à universidade a partir da introdução do sujeito em outros processos formativos, tanto no âmbito formal por meio da escolarização básica, quanto por experiências vivenciadas em outros contextos políticos e sociais. A universidade, assim, corresponde a uma fase no percurso formativo, a qual instrumentaliza formal e sistematicamente o indivíduo com conhecimentos historicamente validados, os quais serão úteis para o exercício profissional, bem como, para a atuação em outras funções no contexto social. Após ter alcançado o título, a formação, como processo permanente, continuará a ser desenvolvida "[...] com formatos mais especializados e vinculados a atuações profissionais mais específicas" (ZABALZA, 2004, p. 28).

Com essa percepção de formação, Zabalza (2004, p. 28), destaca algumas implicações atribuídas à docência universitária no momento atual:

- Incorporação de novos grupos adultos com formações prévias e objetivos de formação diferenciados;

- Necessidade de rever a concepção de formação, destacando sua importância como um processo que ocorre durante o ciclo de vida. A ideia de formação inicial se configura como uma formação básica voltada a estruturar os alicerces de um processo formativo que continua após o término da graduação num formato mais específico a atuação profissional;

- Existe uma intensa orientação profissionalizante da educação superior, o que provocou nos últimos anos, o surgimento de panoramas formativos complementares voltados na sua grande maioria ao exercício da profissão. Ampliou-se também o campo dos agentes de formação, não se resumindo aos professores, mas profissionais em exercício que atendem os alunos no seu período de estágio;

- Rompimento do padrão meramente acadêmico da formação nas universidades, levando-as a ampliarem seu marco de influência sobre a obtenção de competências para o exercício profissional;

- O reconhecimento acadêmico de modalidades de formação não acadêmicas, alcançadas em contextos institucionais não universitários. Já não é mais o diploma por sí só que determina o nível de conhecimento e competência do diplomado;

- Profundas alterações nas estratégias de ensino e aprendizagem utilizadas na universidade, sendo necessários novos procedimentos de ensino semipresencial e a distância, criação de materiais e novas dinâmicas de relacionamento e da rotina estudantil;

- Ampliação da oferta de formação. É exigido não apenas que haja diferentes cursos no sentido de contribuir com a formação inicial dos alunos, mas também que se amplie o número de cursos de especialização, de doutorado e reciclagem para profissionais, etc.

Nesse sentido, o compromisso social da universidade deve se traduzir de forma efetiva, num contexto de aprendizagem reflexiva no processo de construção do conhecimento, dado o entendimento de que o ensino deve ocorrer de forma dialógica com as demandas dos contextos político, social e cultural. Essas implicações sinalizam, portanto, o redirecionar de ações, atitudes e modos de funcionamento das instituições de Ensino Superior frente às constantes modificações no cenário educacional.

Doravante, após essas considerações em torno da universidade de modo ampliado, direcionar-se-á a 
reflexão para um lócus específico, a saber: o contexto dos cursos de Pedagogia da Universidade Federal do Tocantins.

Desta feita, as discussões desencadeadas no II Fórum das licenciaturas: "Os novos desafios curriculares: a formação de professores em discussão" constituiu um ambiente rico de trocas e aprendizagens, de forma que cada curso de graduação (licenciatura), ofertado pela Universidade Federal do Tocantins, fomentou de maneira coletiva um debate profícuo em torno da formação demandada em seus contextos.

A partir do observado, tonou-se explícito a importância e a necessidade da constituição, de modo frequente e recorrente, de momentos como esses, pois, se caracteriza como contributo para se pensar a formação, no âmbito das licenciaturas, de forma ampliada, trazendo para o debate os diferentes agentes que vivenciam cotidianamente os limites, os desafios, e os impasses dos cursos de formação de professores, constituindo, deste modo, uma reflexão que perpassa diferentes olhares consubstanciando um intercâmbio de experiências que auxiliam no processo de análise dos cenários formativos. Os próprios participantes do evento reiteram essa assertiva ao afirmarem que o debate promovido nesse encontro não deveria se limitar apenas a datas esporádicas, influenciadas por necessidade institucional, mas compor um calendário contínuo no contexto da instituição.

Entre os desafios apresentados, situa-se a centralização do evento na capital, o que dificulta a participação de professores e discentes dos câmpus localizados no interior do Estado. Com vista a essa acentuação, a ideia que se configurou nessa ocasião foi à realização de uma nova edição do evento em outro Câmpus, para além da capital.

Diante disso, e como forma de situar e contextualizar o espaço de formação da Universidade Federal do Tocantins acredita-se que seja relevante apresentar alguns dados que configuram essa realidade educacional.

Para fins de ilustração, segue o quadro com a distribuição dos cursos de graduação da referida instituição:

Tabela 1. Oferta dos Cursos de graduação da Universidade Federal do Tocantins

\begin{tabular}{|l|l|}
\hline Total de cursos de Graduação & 64 Cursos \\
\hline Total de cursos de Graduação (Regular/presencial) & 57 cursos \\
\hline Total de cursos (EAD/PARFOR) & 07 cursos \\
\hline Total de cursos de licenciaturas & $\begin{array}{l}33 \text { cursos (51,56\% dos cursos de graduação da UFT são } \\
\text { licenciaturas) }\end{array}$ \\
\hline Total de cursos de Licenciaturas (Regular/presencial) & $\begin{array}{l}26 \text { cursos de Licenciatura (Do total de 33 cursos de } \\
\text { licenciaturas, 26 (78,78\%) são ofertados na modalidade } \\
\text { presencial/regular.) }\end{array}$ \\
\hline Total de cursos de Pedagogia (presencial): & 04 cursos \\
\hline $\begin{array}{l}\text { Câmpus que ofertam o curso de Pedagogia } \\
\text { (regular/presencial) }\end{array}$ & Arraias, Tocantinópolis, Miracema, Palmas. \\
\hline
\end{tabular}

Fonte: Catálogo de cursos da Universidade Federal do Tocantins, 2015.

Com esse contexto de experiências formativas, a promoção do evento, que teve entre os seus objetivos o estímulo ao debate sobre a implementação das novas Diretrizes Curriculares 
Nacionais para a formação de professores (Parecer CNE/CP 2/2015), e a Base Comum Curricular, converteu-se em espaço de elucidação dos desafios encontrados no cenário específico desses cursos.

Deste modo, com um olhar mais atento ao curso de Pedagogia, o GT que trouxe o envolvimento de representantes desse curso, desvelou um conjunto de obstáculos que se apresentam contrários à efetivação de uma formação de qualidade, dentre os quais foram destacados:

- Ausência de conexão entre teoria/prática, levando a dicotomias no decorrer de quase todo o curso;

- Ausência da integração da pesquisa no processo formativo dos discentes;

- Distanciamento da universidade com o contexto das escolas de educação básica, caracterizando uma formação descontextualizada;

- Sobreposição de disciplinas em detrimento de outras, o que provoca a fragmentação do conhecimento a ser construído e o prevalecimento de certos conteúdos;

- Falta de integração entre as disciplinas no decorrer do curso, fruto de uma organização curricular verticalizada;

- A existência de ambientes inibidores da valorização da diversidade, acarretando na exclusão e na marginalização de sujeitos oriundos de diferentes grupos étnicos;

- Esvaziamento de conteúdo, verificando-se um déficit teórico no corpo discente;

- Falta de diálogo entre os cursos para compartilhamento de experiências, causando um afastamento mesmo dentro de uma realidade educacional comum.
Esse rol de desafios apresentados corresponde a uma radiografia do cenário dos cursos de graduação de Pedagogia na Universidade Federal do Tocantins, representando uma preocupação dos docentes formadores de como superá-los, uma vez que a partir da análise, realizada de forma coletiva, esses são desafios que não são novos, estão arraigados historicamente nesses cursos.

A explicitação desses desafios vai ao encontro da acepção proposta por Libâneo (2009, p.09) ao assinalar que,

\begin{abstract}
A atividade docente no ensino superior se defronta com dilemas frente a necessidades sociais e individuais de formação profissional num mundo em mudança. Estão em curso, em nível global e local, transformações econômicas, sociais, políticas, culturais, éticas, que, atuando em conjunto, repercutem em várias esferas da vida social como a organização do trabalho, as formas de produção, a formação profissional.
\end{abstract}

Verifica-se, portanto, que o conjunto desses dilemas, apontados pelos docentes, são reflexos de um movimento amplo acarretado por mutações contemporâneas, os quais não se restringem apenas a uma dimensão da educação, mas reverberam nos diversos campos dos sistemas educativos e das instituições de ensino, perfazendo suas configurações e reorientando os caminhos na busca de soluções e desdobramentos outros que incitem o avançar contínuo no processo de formação.

Diante dessas considerações, foi explicitado, constantemente, nos discursos dos docentes presentes no encontro, que o modelo de formação, vivenciado na universidade no momento atual, não contempla uma formação suficiente para o perfil profissional exigido para o contexto educacional da contemporaneidade, o que corrobora com o que destaca Nicolescu (1999, p. 141), ao enfatizar que vivemos " [...] um sistema de educação baseado nos 
valores de outro século, cada vez mais defasado em relação às mutações contemporâneas". Fato este, que exige uma reflexão acerca de como situar a universidade, como instituição social formativa, a partir de bases mais coerentes e ancoradas nas dimensões do contexto atual.

Nessa perspectiva, há a necessidade de uma formação que se posicione de maneira atenta às demandas oriundas da realidade concreta da sociedade, que se proponha a romper com o paradigma da modernidade (paradigma conservador) que, firmando o formato da educação na lógica positivista, instaurou um modelo de formação que se encontra descompassado com as transformações que delinearam o cenário atual, e esse desequilíbrio, entre o pensamento e as vivências no campo da realidade, tem caracterizado e consubstanciado os atuais desafios e obstáculos encaminhados para a educação, pois conforme Nicolescu (1999, p. 141) "os abalos que permeiam o campo da educação, num ou noutro país, são apenas os sintomas de uma única e mesma fissura entre os valores e as realidades de uma vida planetária em mutação".

É necessário considerar, também, a complexidade da educação superior, cujo julgamento ultrapasse os enfoques meramente econômicos, respeitando a necessidade de manter o equilíbrio da sociedade na sua totalidade. O papel da universidade precisa ser significativo no sentido de contemplar uma formação que possibilite ao indivíduo uma construção crítica acerca do conhecimento.

Nesse sentido, Pimenta e Anastasiou (2002, p. 103-104), destacam que o ensino na universidade perpassa pelos seguintes arranjos:

a) domínio de um campo de conhecimento e técnicas científicas que devem ser ensinados criticamente; aumento da autonomia do aluno na busca do conhecimento; ampliação da capacidade de reflexão e domínio científico e profissional do campo específico;

b) necessidade de considerar o processo de ensinar e aprender como uma atividade associada ao processo de investigação;

c) mudança do ensino que simplesmente transmita conteúdos por um ensino que institua um processo de investigação do conhecimento;

d) associar a atividade de investigação à atividade de ensinar, o que pressupõe a realização de um trabalho coletivo;

e) procurar criar e recriar as condições de aprendizagem;

f) buscar valorizar a avaliação diagnóstica superando o entendimento de uma avaliação como controle;

g) buscar conhecer a natureza cognitiva e cultural dos alunos, a fim de ampliar os processos de ensino e aprendizagem buscando participação.

Cabe destacar que essas características, intrínsecas ao processo de ensinar, promovem ajustes junto aos resultados do ensino, bem como uma boa preparação nos campos dos conhecimentos pedagógicos.

Essa reflexão, pontuada pelas autoras, traz à tona a necessidade do debate acerca das configurações das instituições educativas, visto que essas “devem ser instituições "vivas", promotoras da mudança e da inovação" (IMBERNÓN, 2011, p. 64, grifo do autor), com vistas à proposição de caminhos que situem um projeto formativo alicerçado em uma dimensão provedora de mudanças significativas, considerando a importância do trabalho a ser desenvolvido a fim de permitir, pelo aprendizado da reflexão, a constante construção e reconstrução do conhecimento como um movimento dinâmico que jamais se esgota. 


\section{REFLETINDO ASPECTOS DA FORMAÇÃO DO PROFESSOR: BREVES APONTAMENTOS}

Quando falamos no sentido formativo da universidade isso nos remete a refletir sobre a formação como uma função básica da docência, o significado dessa formação no contexto universitário, e de como essa concepção afeta o desenvolvimento das atividades docentes no interior das instituições. Com isso, é importante iniciar indagando: Afinal, o que entendemos quando destacamos que a função básica dessa instituição é a formação? A esse respeito, Zabalza (2004), destaca alguns pontos que para ele possuem estreita relação com o real significado da formação e com as mudanças que afetam o âmbito institucional no momento atual: Primeiramente, a integração da universidade no centro das dinâmicas sociais. Em segundo, o acesso de diferentes grupos sociais ao ensino superior, e, por último, a ampliação dos períodos formativos para além dos espaços institucionais formais.

Com efeito, nessas proposições está implícita uma intensa revisão do tradicional significado de formação e desenvolvimento pessoal. Dado o fato de que, o crescimento das exigências de formação tem reivindicado profundas mudanças quanto à concepção e estratégias para sua realização.

Sob esse prisma é válido ressaltar que a discussão sobre formação, não costuma ser algo rotineiro nos estudos no âmbito educacional e termos como educação, ensino, instrução e treinamento estiveram presentes no vocabulário pedagógico. A referência feita à expressão "formação" apareceu com mais intensidade ligada à formação profissional e nem mesmo nesse caso houve esforços para entender o seu real sentido (ZABALZA, 2004). O que encaminhou para a produção de um vazio em relação à ideia de formação, sendo definida, com frequência, mais ao que se ofertou do que ao efeito exercido sobre os sujeitos que dela participam.

No território brasileiro, o que se observa é que a formação de professores perpassou por modelos ideológicos distintos, desde concepções tecnicistas à racionalidade prática, levando, no panorama atual, a necessidade de uma proposta formativa que transcenda essa lógica empirista. Conforme (IMBERNÓN, 2011, p. 15)

\begin{abstract}
Nesse contexto, a formação assume um papel que transcende o ensino que pretende uma mera atualização científica, pedagógica e didática e se transforma na possibilidade de criar espaços de participação, reflexão e formação para que as pessoas aprendam e se adaptem para poder conviver com a mudança e a incerteza.
\end{abstract}

Portanto, falar em formação, atualmente, preside o estabelecimento de quais ideais, que tipo de habilidade e que profissional se almeja formar para a educação do presente e do futuro, tendo a clareza das incertezas e adversidades que se colocam como intrínsecas nesse processo.

Nessa lógica, é notório enfatizar que houve muitas mudanças na educação superior nos últimos anos, com destaques que vão desde a massificação e progressiva heterogeneidade dos estudantes até a redução de investimentos, da nova cultura da qualidade às novas perspectivas na formação, de uma orientação centrada no ensino para uma organização centrada na aprendizagem, abrangendo também as novas tecnologias e a educação à distância. E de certa forma refletiu no modo como as universidades dispuseram seus recursos e rediscutiram suas propostas de formação Zabalza (2004).

Uma nova visão de sociedade, na qual se confere valor particular ao conhecimento, que se encontra em plena reconstrução, certamente deverá conferir à universidade o papel de agente de mudança no sentido atribuído à formação, alicerçando-a na perspectiva de processo, ressaltando a sua 
importância como elemento permanente que não se limita ao espaço acadêmico. Pois, conforme Nóvoa (1997, p.28):

[...] O professor forma a si mesmo através das suas inúmeras interações, não apenas com o conhecimento e as teorias aprendidas nas escolas, mas com a prática didática de todos os seus antigos mestres e outras pessoas, coisas e situações com as quais interagiu em situações de ensino durante toda a sua vida.

Com essa perspectiva, a formação, é entendida como parte da vida do professor e depende do seu desenvolvimento, do seu fazer, propiciando mudanças não somente no seu percurso formativo, mas na sua prática como professor e na maneira como percebe o mundo. Assim, ela deverá contribuir para o aperfeiçoamento e crescimento das pessoas no sentido integral, ou então não haverá sentido falar de formação se não sob a prerrogativa do crescimento como pessoa num constante movimento de construção.

Nesses termos, estar em formação implica um investimento pessoal com vistas à construção de uma identidade profissional. Diante disso, concorda-se com Nóvoa (1992), quando destaca que a formação deve possibilitar uma perspectiva crítico-reflexiva que por meio de um pensamento independente facilite as dinâmicas de auto formação.

$\mathrm{Na}$ formação, o processo de reflexão, reconstrução, troca de experiência e capacidade de aprender sempre aparecem como condições formativas contínuas, de forma que os docentes se reconheçam e sejam autores das suas práticas e do processo de seu ensinar e aprender. Desta feita, a formação não pode se apresentar como uma ação casual e de compensação, e sim como parte complementar do exercício profissional, no sentido de propiciar aos docentes a reflexão acerca de suas próprias práticas.
De acordo com Nóvoa (2007), o docente do ensino superior possui alguns desafios. Inicialmente, o desafio de colocar em prática o conceito de um melhor aparelhamento da profissão docente, seguido da carência de formação mais voltada para as práticas e suas análises. Destaca ainda, que a formação do docente que é, por vezes, demasiadamente de cunho teórico num viés metodológico, acaba por apresentar poucas práticas de reflexão sobre o próprio trabalho, num constante desafio de saber como proceder, como fazer. Assim sendo, o professor deve estar vigilante ao desafio de não simplesmente reproduzir o que porventura tenha sido elemento de seu processo de formação formal, o que muitas vezes acontece seja pela insegurança ou por não saber fazer de outra forma.

Um grande dilema posto ao professor é admitir que não aprendeu na prática "como fazer" quando ele ainda frequentava o ensino superior. Pois, uma vez assumida essa fragilidade pode acabar levando-o a um lugar de desprestígio e julgamento frente aos demais colegas e até mesmo pelas próprias instituições de ensino, e assim, não raras vezes, passa a ter seu trabalho profissional interrogado.

Quando falamos do ser trabalhador, portanto, do professor como agente profissional, logo pensamos que o mesmo é intrínseco do seu fazer, do seu agir. Para Nóvoa (1992), o ser professor nos leva a opções constantes que atravessam a nossa maneira de ser com a nossa maneira de ensinar, e que revelam na maneira de ensinar a nossa maneira de ser.

Nesse cenário, o professor não pode se tornar refém de determinados modelos teóricos e sim se sentir provocado cotidianamente a superar e buscar rever certos modelos, no intuito de refletir e inovar suas práticas, primando pelo seu bom desempenho e a qualidade do ensino. 
A sociedade de uma forma geral deseja que o professor atue de forma comprometida e seja competente e contemporâneo. Desse modo, o mesmo precisa agir como um mediador entre o conhecimento e seus alunos, devendo apropriar-se de técnicas e recursos diversificados, objetivando acompanhar o processo de aprendizagem percorrido pelos alunos e as dificuldades e progressos alcançados.

Destarte, refletir sobre a docência no Ensino Superior remete inevitavelmente ao processo de formação para atuar na docência universitária, levando em consideração os aspectos teóricos e práticos, procurando compreender a disposição de saberes necessários ao exercício da docência, a fim de buscar uma formação pedagógica atualizada que evidencie um processo formativo ampliado, abrangendo tanto o âmbito profissional como também pessoal dos sujeitos.

As considerações assinaladas levam a pensar que, diante dos desafios que se apresentam, faz- se salutar uma mudança, ontológica, epistemológica, metodológica no modo como a universidade, espaço historicamente privilegiado da racionalidade, da ciência pura e despido da subjetividade, é pensada na atualidade. E mudar não significa descartar o que foi construído, pois, os novos olhares $[\ldots]$ não desconsideram os velhos (olhares) por entender que eles foram/ serão necessários ao surgimento do novo. (PEREIRA; PINHO, 2015, p. 48). É, no entanto, necessário avançar rumo a um projeto de universidade que se apresente como contemporâneo aos modos de viver e conceber a realidade que nos circunda, evoluindo frente ao modelo do pensamento positivista que impregna as propostas de formação, e que vem provocando graves incongruências.

\section{À GUISA DE CONCLUSÃO}

$\mathrm{O}$ atual contexto requer que a universidade esteja organizada para responder às necessidades da contemporaneidade. Retomando o objetivo deste trabalho, que busca provocar reflexões acerca do papel da universidade na formação de professores, podemos destacar que se faz urgente o debate coletivo acerca das mudanças que se apresentam como indispensáveis para o projeto formativo desta instituição, com vistas a colaborar, a partir de sua função social, com os progressos da educação, no contexto da formação, no descortinar da contemporaneidade que apresenta contundentes modificações na sociedade como um todo.

$\mathrm{O}$ exposto nas reflexões apontadas pelo conjunto de autores elencados na presente discussão: ZABALZA (2004), IMBERNÓN (2011), NÓVOA (1992, 2007), NICOLESCU (1999); PIMENTA e ANASTASIOU (2002), LIBÂNEO (2009) abordam um cenário da universidade em seu sentido amplo. Contudo, ao analisar as especificidades da UFT verifica-se que os dilemas, desafios e características apontadas por eles, acerca da universidade, são vivenciados no contexto da Universidade Federal do Tocantins. Dentre eles, pode-se citar:

- O grande quantitativo de discentes, que na graduação da referida realidade educacional, remonta-se ao total de $15100^{2}$ estudantes matriculados. O que faz com que essa instituição organize seu espaço para atender um público cada vez mais heterogêneo;

- Emerge a necessária reorganização das práticas docentes frente à inserção, no ensino, de novas tecnologias, e do crescente número de cursos

\footnotetext{
${ }^{2}$ Quantitativo de docentes matriculados no $2^{\circ}$ semestre de 2016 nos cursos de graduação da Universidade Federal do Tocantins. Dado fornecido pela Pró-reitoria de Graduação (PROGRAD).
} 
em formatos de formação EAD, a UFT possui em seu contexto cursos com essa característica;

- A necessidade de inserção da pesquisa no processo formativo nos cursos de formação de professores, acentuada pelas falas dos docentes formadores no decorrer do evento supracitado;

- A reorganização dos currículos de forma que a articulação disciplinar seja vertical e horizontal;

- A emergência do trabalho coletivo entre seu corpo docente como forma de promover $\mathrm{o}$ enriquecimento do trabalho desenvolvido na universidade.

Com base nessa conjectura, afirma-se que esses são apenas alguns elementos que perfazem o universo institucional da UFT, que pelo exposto encontra-se em concordância com várias das características da universidade - em seu sentido genérico- acentuadas pelos autores.

Face ao exposto, faz-se necessária à criação de condições que propiciem a implementação de um projeto de formação capaz de promover diferentes possibilidades de desenvolvimento profissional, novos conhecimentos e habilidades, novas atitudes e valores e por fim, o enriquecimento e ampliação das próprias experiências dos sujeitos.

Ao destacar as discussões desencadeadas no evento ocorrido no contexto da Universidade Federal do Tocantins, abriu-se possibilidade para o repensar da própria formação de professores encaminhadas atualmente no contexto desta instituição de ensino, contribuindo, com o caráter de provocação e estímulo, o desencadeamento de um debate que busque a construção de outras alternativas para o processo formativo dos profissionais docentes.

Entende-se, pois, que a função formativa da universidade na perspectiva de formar o estudante para o mundo de hoje, perpassa pelo caminho defendido por Delors (2012) em seu trabalho: "Educação um tesouro a descobrir", em que aponta os quatro pilares formativos da educação para o século XXI: aprender a aprender, aprender a fazer, aprender a ser e a aprender a conviver. O desafio que nos é apresentado é como implementar essas ideias num projeto de formação que atenda as particularidades das universidades.

Assim, formar na perspectiva de enfrentamento dos desafios que estão cada vez mais explícitos, é antes de tudo aderir conscientemente a uma proposta que motive o debate coletivo, a adesão de novas práticas, tanto no âmbito organizacional, curricular, como de ação pedagógica, e ter atitude para o desencadear de novas proposições, reconhecendo os limites que são apresentados pelos modelos de formação que, preconizam uma visão reducionista, segregada, estática do conhecimento e da própria realidade que nos rodeia.

Espera-se que as considerações aqui apresentadas possam contribuir com as reflexões a respeito da temática, dada a importância das universidades assumirem a formação nas dimensões da dinâmica do desenvolvimento pessoal, aprimoramento dos conhecimentos e capacidades dos indivíduos em um contexto de constantes incertezas e adversidades. Ressalta-se que o artigo não teve a pretensão de apresentar respostas, mas de provocar reflexões e estimular àqueles que acreditam que a educação, e consequentemente, a formação docente, não é um elemento estático, mas um processo em plena construção, e, portanto, aberto a novas e melhores alternativas.

Todos os autores declararam não haver qualquer potencial conflito de interesses referente a este artigo. 


\section{REFERÊNCIAS}

BARRETO; Sidirley de Jesus; HERMIDA, Jorge Fernando Aveiro; SOUSA, Clóvis Arlindo de. A criatividade como suporte da aprendizagem no ensino superior do século XXI. In: ZWIEREWICZ, Marlene (coord.). Criatividade e inovação no ensino superior. Blumenau, SC: Nova Letra, 2013, p. $83-$ 100.

BRASIL. Resolução $\mathbf{N}^{\circ}$ 2, DE $1^{\circ}$ DE JULHO DE 2015. (Define as Diretrizes Curriculares para a formação inicial em nível superior (cursos de licenciatura, cursos de formação pedagógica para graduados e cursos de segunda licenciatura) e para a formação continuada). Brasília, MEC/CNE, 2015.

CATÁLOGO DE CURSOS DA UFT. Palmas, 2015. Disponível em: http://ww1.uft.edu.br/index.php/ensino/graduacao/cat alogo-de-cursos. Acesso em: 15/03/2016.

DELORS, Jacques. Educação um tesouro a descobrir. Brasília: Cortez, 2012.

NICOLESCU, Basarab. O Manifesto da Transdisciplinaridade. Tradução de Lucia Pereira de Souza. São Paulo: TRIOM, 1999.

IMBERNÓN, F. Formação docente e profissional: formar-se para a mudança e a incerteza. 9.ed. São Paulo: Cortez, 2011.

LIBÂNEO, José Carlos. Conteúdos, formação de competências cognitivas e ensino com pesquisa: unindo ensino e modos de investigação. Cadernos de Pedagogia Universitária. 2009. Disponível em: www.prpg.usp.br/prpg/attachments/article/640/cader no_11_PAE.pdf. Acesso: 05 out. de 2016.

MORIN, Edgar. A cabeça bem feita: repensar a reforma, reformar o pensamento. 7. ed. Rio de Janeiro: Bertrand do Brasil, 2002.

NÓVOA. A. Formação de Professores e profissão docente. In A. Nóvoa (coord.) (1997). Os professores e a sua formação. Lisboa: Dom Quixote, 3 ed. 1997.

Os professores e a sua formação.

Lisboa: Dom Quixote. Instituto de Inovação Educacional, 1992.

Formação de Professores e Qualidade do Ensino. Revista Aprendizagem: a revista da prática pedagógica. v.1, n.2, set/out, 2007.
PEREIRA, Fabíola Andrade; PINHO, Maria José de. Política de formação docente do curso de PedagogiaPARFOR: construindo novas possibilidades. In: NETO; Armindo Quillici Neto; SILVA, Fernanda Duarte Araújo; SOUZA, Vilma Aparecida (orgs.). Formação de professores: perspectivas e contradições. Uberlândia: Composer, 2015.

PIMENTA, Selma Garrido. ANASTASIOU, Léa das Graças Camargos. Docência no Ensino Superior. São Paulo: Cortez, 2002.

SANTOS, Boaventura de Souza. A universidade do Século XXI: para uma reforma democrática e emancipatória. São Paulo: Cortez, 2004.

ZABALZA, Miguel A. O ensino universitário: seu cenário e seus protagonistas. Porto Alegre: Editora Artmed, 2004. 